\title{
SENILE ANKYLOSING HYPEROSTOSIS OF THE SPINE*
}

\author{
BY \\ J. FORESTIER and J. ROTES-QUEROL
Aix-les-Bains and Barcelona
}

Our attention has been drawn to an ankylosing disease of the spine developing in old people, with a painless onset and clinical, pathological, and radiological features distinguishing it from ankylosing spondylitis.

Some descriptions of anatomical specimens in the literature seem similar to those we have found, but no clinical or radiological studies on this subject have been published. Léri (1904) describes pathological changes in the spine of a patient suffering from a condition to which Marie and Astié (1897) gave the rather unsatisfactory name of " heredo-traumatic kyphosis of Bechterew", and these coincide with our observations; but in Léri's case the patient, an old man, had an angular kyphosis of the Kümmel-Verneuil type consequent upon a fall. Meyer and Forster (1938) have described a similar anatomical condition under the name of "moniliform hyperostosis" affecting the right side of the dorsal spine. Oppenheimer (1942) noticed some ossification of vertebral ligaments in old people without involvement of the joint facets. These patients had adequate vertebral mobility and no symptoms. He considered that these features belonged to the type of ossification associated with ankylosing spondylitis. Lacapère (1949) in his study of osteophytosis of the spine in dried bones often mentions outgrowths which he calls " melorheostosis of the spine", a term that may lead to confusion with the disease described under this name by Léri. The anatomical description given by Lacapère coincides roughly with those of the other writers and also with that here presented.

\section{Present Investigations}

The clinical and radiological study of nine cases, combined with necropsy findings in two specimens, has enabled us to set out some of the clinical, pathological, and radiological features, and to form a picture of a specific condition among the ankylosing diseases of the spine.

\section{Clinical Examination}

Age.-The disease has been seen only in persons between 50 and 73 years of age (average 65), an incidence quite different from that of ankylosing spondylitis, which is usually seen in young and middle-aged persons. The age of onset is difficult to fix precisely (except in cases with a clear history of trauma) in view of the insidious evolution of the disease.

* This paper was presented at the joint meeting of the Ligue Française contre le Rhumatisme and the Heberden Society held in Paris, June, 1950. 
Sex.-All these patients were men.

Symptoms.-The usual symptom is a stiffness of the spine, always involving the dorsal but often also the lumbar region; it spread to the cervical region in only three of our cases (the three with a history of trauma). The stiffness causes moderate discomfort, generally well tolerated by the patient. The condition is usually painless, and therefore latent. Three of our cases had had a brief attack of lumbago or of sciatica. If pain was present, its severity bore no relation to the degree of stiffness. We found no significant changes in posture. In two cases, there was a slight dorsal kyphosis of the type usually seen in old people. The peripheral joints were not involved except in two cases with osteo-arthritis of the knees, a finding common in elderly patients. The disease is therefore limited to the spine.

The general condition was satisfactory in view of the advanced age of the subjects; six were obese, the others of normal weight. The erythrocyte sedimentation rate was normal in all except one patient, who had chronic bronchitis. Alkaline phosphatase values measured in two cases, by Bodansky's method, were $6 \cdot 5$ and $5 \cdot 3$ units respectively, that is to say almost normal.

Radiological Examination. (Made with the assistance of F. JACQUELINE.)

SPINE.-The lateral views give rise to these observations:

Dorsal Region.-The most characteristic appearances of the dorsal spine are to be seen in the lateral view. There is a continuous but irregular flowing outgrowth (coulée continue) alongside the anterior aspect of the vertebrae and the disks of the dorsal spine, usually from D4 downwards. (In one case the outgrowth reached the cervical spine.) At the level of the dorsal vertebrae, it is a few millimetres to one centimetre thick and the antero-posterior diameter of the vertebrae is then enlarged to such an extent that they seem to - be flattened. More often, the anterior edge of the body is clearly visible at the posterior limit of the outgrowth. At the level of the disk, the outgrowth thickens into a large swelling a few centimetres thick. The disks

Fig. 1.-Case S. Lateral dorsal view. Anterior hyperostosis or outgrowth (coulee) from D4 covering the disks and vertebral bodies. The anterior edges are visible. are usually of normal height; they do not protrude into the swellings which are of homogeneous density (Fig. 1).

Lumbar Region.- In lateral views of the lumbar spine the outgrowths can be seen on the anterior aspect, but here they are often discontinuous, being interrupted at the level of the disks, or bent away as if recoiling from them. This causes a peculiar shadow, shaped like a candle-flame, the apex of which may reach far up in front of the vertebral body just above. The anterior edges of the bodies are clearly outlined and may be clearly distinguished from the protuberance (Figs 2 and 3). When visible in the radiograph, the spinous processes show a thickening of the supraspinous ligament, often very clearly defined on the posterior side, where a bony link may be formed between adjacent vertebrae. The structure of the protuberances is fairly homogeneous, but their texture is not apparent. 


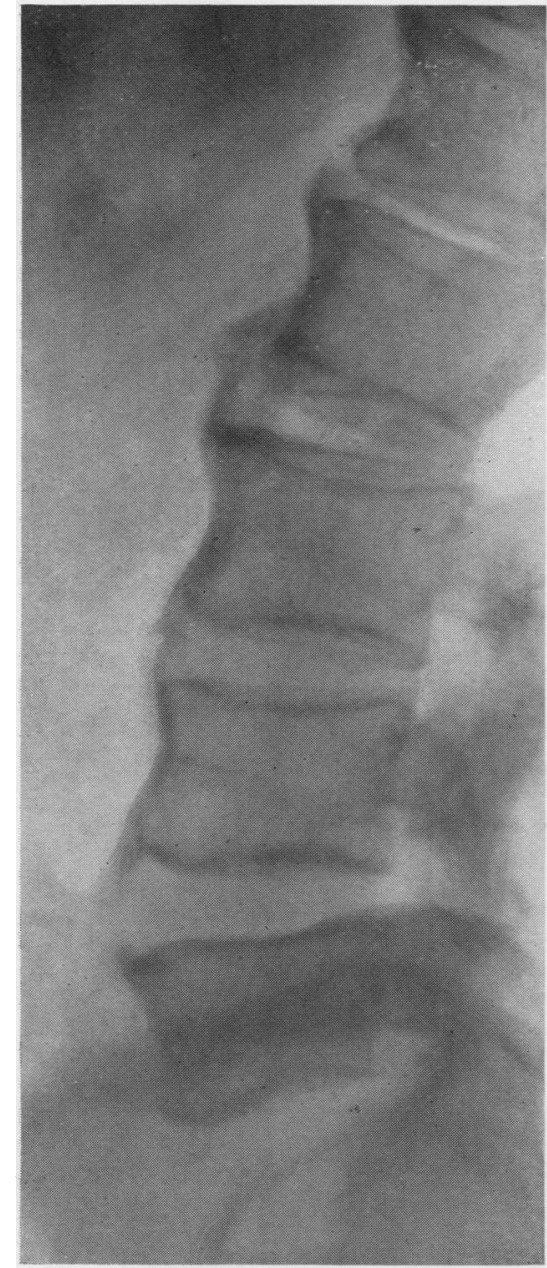

Fig. 2.-Case S. Lateral lumbar view. Anterior outgrowth covering the disks and vertebral bodies. It is interrupted at the level of several disks.

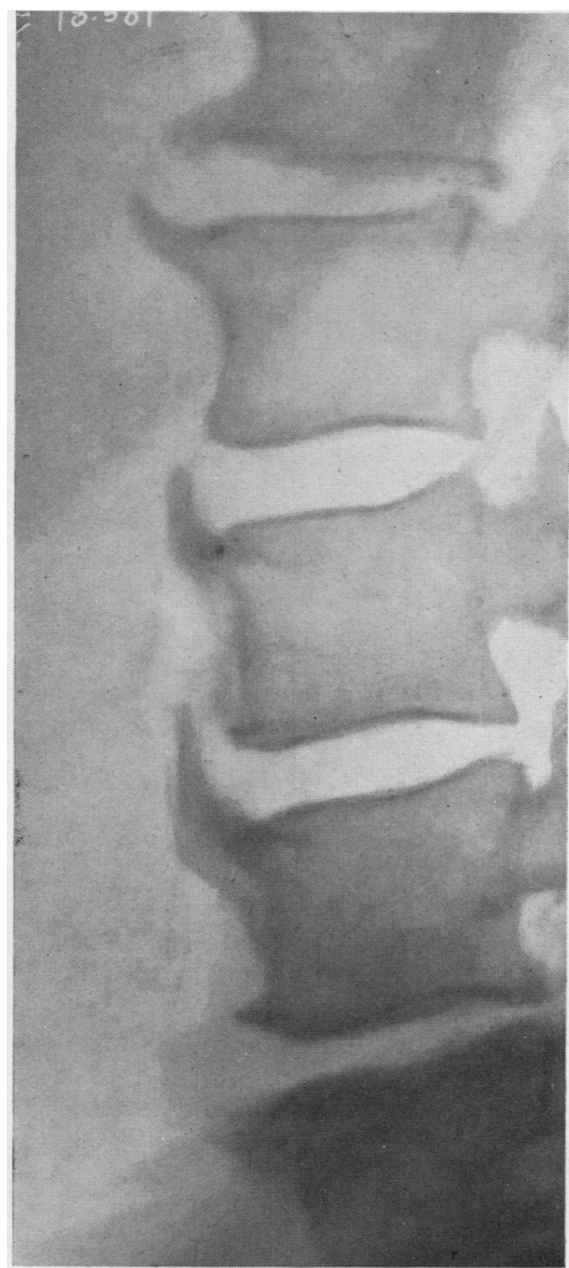

Fig. 3.-Case P. Lateral lumbar view. "Candle-flame" hyperostosis. At the level of L3 and L4 the base of the hyperostosis covers the anterior side of the vertebral body.

Cervical Region.--In two cases in which we have studied lateral views of the cervical spine, large bony outgrowths on the anterior aspect of the vertebral bodies have been observed. The formations are not continuous but are separated from one another by clear spaces at the level of the disks. These outgrowths are thickly spaced opposite the middle part of the bodies, which seem enlarged antero-posteriorly. This discontinuous aspect of the bony outgrowths in the cervical region is similar to that in the lumbar region; it contrasts with the continuity in the dorsal area, and must be related to the greater mobility of the lumbar and cervical spine.

In frontal views of the dorsal and lumbar spine, the appearances are less characteristic and their interpretation is more difficult. The protuberances are not clearly visible on the lateral edges of the spine, but may appear as little bridges, chiefly on the right side. 
In some cases, these bridges may be quite large in the dorso-lumbar segments, and the picture may resemble that of ankylosing spondylitis. However, the striking contrast between the obvious protuber-

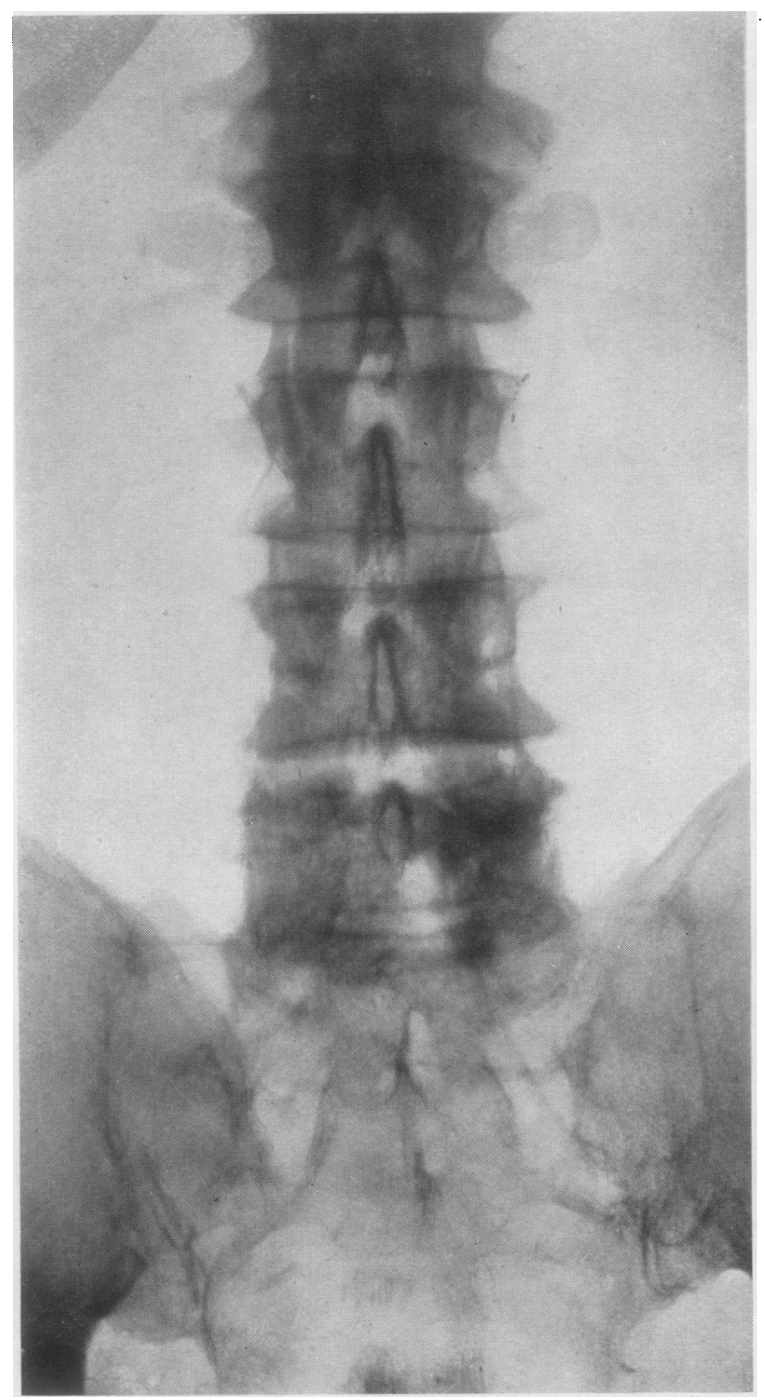

FIg. 4.-Case P. Frontal lumbar and sacro-iliac view. "Dense and woolly bony structure" at the level of L3, 4, and 5 , owing to the superimposition of the hyperostosis upon the anterior faces of the vertebrae (see Fig. 3). Sacro-iliac joints normal. ance developing on the front of the spine and visible in lateral films, and the minor lateral protuberance seen in antero-posterior films, is one of the most important elements in the diagnosis. In ankylosing spondylitis, the syndesmophytes are more clearly visible in antero-posterior films than in lateral films.

A second striking appearance due to the anterior position of the protuberance is the change in structure of the vertebral body which is visible in frontal views and is due to the superimposition of the picture of the outgrowth upon that of the body.

The vertebral bodies have a " woolly" aspect, more or less dense and grained, which may lead to confusion with neoplasms, Paget's disease, etc. A lateral view shows the superimposition upon the front of the vertebral bodies of a protuberance about $1.5 \mathrm{~cm}$. thick, which is obviously the cause of the apparent change in structure seen in antero-posterior films (Fig. 4).

Pelvis.-In the antero-posterior view of the pelvis the sacro-iliac joints show no pathological alterations (Fig. 4). We have never found joint fusion or the picture of inflammatory arthritis. This finding is in contrast to the bilateral sacro-iliac changes seen in patients with ankylosing spondylitis. The edge of the iliac crest is more obvious than usual and seems thickened, sometimes all the way down from the antero-superior spine to the postero-superior spine.

The increase in density at this level, involving one-third of the sacro-iliac joint, may lead to a false picture of joint fusion.

HANDS AND LIMBS.-Radiographs of the hands and limbs showed no significant difference 
in peripheral involvement and in changes in the periosteum between this and other more familiar diseases.

Certain notable points of difference between this disease and ankylosing spondylitis are tabulated below:

\begin{tabular}{|c|c|c|}
\hline Points of Comparison & Ankylosing Hyperostosis & Ankylosing Spondylitis \\
\hline Age of Onset & Old age & Youth or middle age \\
\hline \multirow{5}{*}{ Clinical Examination } & $\begin{array}{l}\text { Normal spinal statics } \\
\text { Spinal stiffnessi n dorsal region } \\
\text { often does not involve } \\
\text { cervical region }\end{array}$ & $\begin{array}{l}\text { Kyphosis in } 63 \text { per cent. of cases } \\
\text { Lumbar and dorsal ankylosis } \\
\text { often involves cervical region }\end{array}$ \\
\hline & No spinal pain & Severe pain in almost all cases \\
\hline & $\begin{array}{l}\text { No peripheral joint involve- } \\
\text { ment }\end{array}$ & $\begin{array}{l}\text { Peripheral joint involvement in } \\
72 \cdot 5 \text { per cent. of cases }\end{array}$ \\
\hline & No invalidism & Frequent invalidism \\
\hline & $\begin{array}{l}\text { Erythrocyte sedimentation } \\
\text { rate normal }\end{array}$ & $\begin{array}{l}\text { Erythrocyte sedimentation rate } \\
\text { accelerated in } 75 \text { per cent. of } \\
\text { cases }\end{array}$ \\
\hline \multirow{3}{*}{$\begin{array}{l}\text { Radiological } \\
\text { Examination }\end{array}$} & $\begin{array}{l}\text { Protuberance visible mainly } \\
\text { in lateral films }\end{array}$ & $\begin{array}{l}\text { Syndesmophytes visible mainly in } \\
\text { antero-posterior films }\end{array}$ \\
\hline & $\begin{array}{l}\text { Thick bulge over the whole } \\
\text { height of the vertebral body }\end{array}$ & $\begin{array}{l}\text { Ossification existing only at the } \\
\text { level of the superior and the } \\
\text { inferior thirds of the vertebral } \\
\text { body adjacent to the inter- } \\
\text { vertebral space }\end{array}$ \\
\hline & Sacro-iliac joints normal & Sacro-iliac joints pathological \\
\hline
\end{tabular}

The following points are important in differentiating between this disease and spinal osteo-arthritis:

(1) There is no question of confusion at the level of the dorsal spine: there, the swellings, unbroken, and covering the disks and the bodies, which are seen in lateral films in cases of hyperostosis, are entirely different from the usually small osteophytic spurs of spinal osteo-arthritis.

(2) In the lumbar region there are two possibilities:(i) there is a continuous outgrowth and no diagnostic problem arises; (ii) the outgrowths are independent of one another and may be mistaken for osteophytes. In the latter event they may be distinguished by the following features (Fig. 3):

(a) They have a wide base, consisting of a part or the whole of the height of the anterior aspect of the vertebral body.

(b) The outgrowth spreading from the whole of the anterior aspect of the vertebral body extends upwards; large spurs starting from the lower edge of the vertebra and projecting downwards are never seen.

(c) The disks are usually of normal height.

Diagnosis is sometimes difficult because the hyperostosis develops in old persons and there are often pre-existing osteo-arthritic changes to which the hyperostosis 
is added (Fig. 2). ${ }^{*}$ The continuous swelling seen in lateral films of the thoracic spine will, however, enable a correct diagnosis to be made.

Post-Mortem Study.-We next reviewed the pathological and radiological data collected by one of us (J.F.) before 1939 on necropsy specimens of vertebrae obtained from elderly persons. Comparing the radiographs of these specimens with those of cases in our clinic, we decided that two of them showed signs of the disease, and were thus able to proceed to define its pathological, clinical, and radiological features.

\section{Specimen A}

Post-Mortem Examination.-There is a complete range of mobility in all directions, but the dorsal segment is fixed.

A bony protuberance with regular corrugations, located on the right side of the dorsal spine from D3 to D11, is continuous, follows the shape of the spine, and is grooved by the blood-vessels from the aorta. These vessels can be seen in the readily retracted fibrous sheet (perirachis). The bony outgrowth has the consistency and colour of bone, being compact, nacreous, and white, like the femoral diaphysis. It is occasionally perforated by vascular nutrient foramina. Though it is unilateral, it shows extensions at the levels of the intervertebral spaces D7/D8, D8/D9, and D9/D10.

The anterior vertebral common ligament (Fig. 5) is clearly visible. It is drawn to the left by the outgrowth, and the spurs described above are located beneath it. This ligament may easily be detached from the spurs though it is firmly attached at the level of the vertebral bodies as well as at the level of the disks.

The costo-vertebral, interapophysial, and sacro-iliac joints retain their mobility.

$X$-Ray Examination. - In the lateral dorso-lumbar view, a considerable protuberance extends in front of the bodies and disks from D4 to D12. It seems to be joined to the front of the vertebrae and a narrow space is visible between the posterior aspect of the outgrowth and the anterior aspect of the vertebrae (Fig. 6).

In the oblique dorso-lumbar view, we see this protuberance again. No line of separation between the front of the vertebrae and the bony outgrowth can be distinguished; at some levels it appears to be fused with the vertebral bodies and there is no break between them and its cancellous bone.

The difference between the lateral and oblique views may perhaps be explained by the position of the hyperostosis of the vertebral bodies. The outgrowths are situated on the right antero-lateral aspect of the circumference of the vertebral bodies. In the lateral view two tangential surfaces are seen: (a) that of the front of the body, and $(b)$ that of the front of the hyperostosis. In the oblique view, only one tangential line is seen; the hyperostosis, being anterior to the body, appears in the picture. In this oblique view the base of the hyperostosis is visible, and the $x$-ray films show that at this level there is no separation of hyperostosis and vertebral body. The cancellous part of the hyperostosis and that of the vertebral body are continuous. This explanation makes comprehensible the apparent "juxtaposition" of the hyperostosis in the lateral films.

A protuberance appears on the right side of the front of the spine; bridges are outlined. The vertebral bodies cast a darker shadow on the right side than on the left.

\section{SPECIMEN B}

Post-Mortem Examination.-(Age of subject not known.) The dorsal curvature is normal, but the dorsal segment is almost ankylosed, spinal movement being very limited. The bony outgrowth is situated between D7 and D11, on the right side of the spine; it is a hard, nacreous outgrowth with a consistency similar to that of the cortex of the femur,

\footnotetext{
* A misinterpretation of this kind has been made by Comroe (1949).
} 


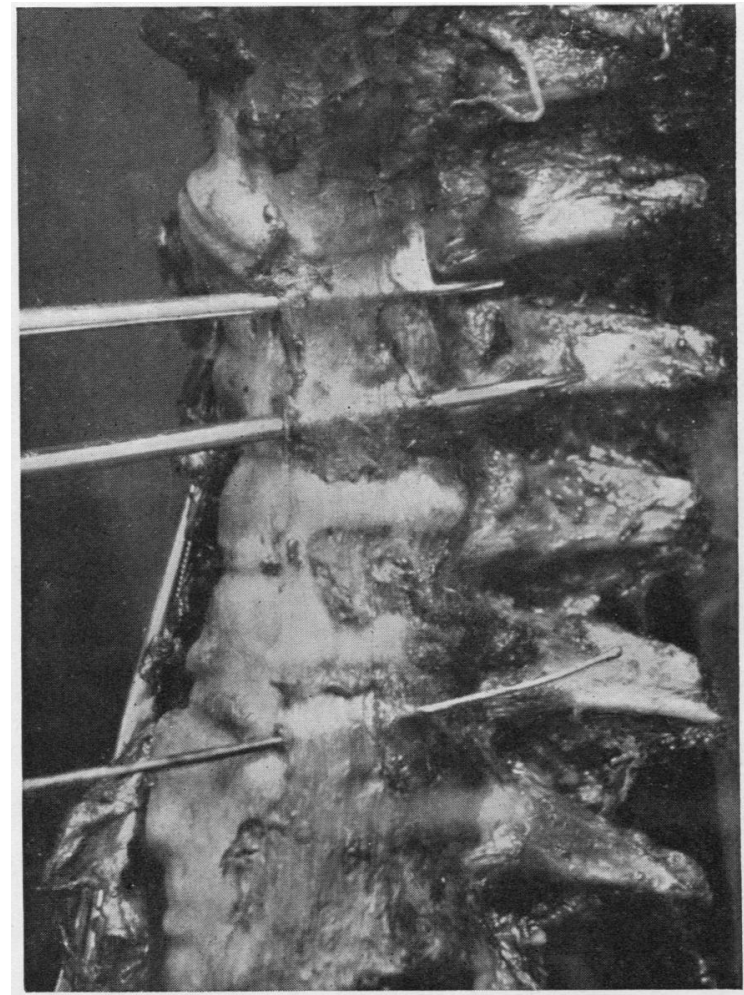

FIG. 5.-Specimen A. Left side. The anterior vertebral common ligament is pushed to the left by the bony formation. The extensions or tongues of the spurs of the hyperostosis can be seen on the left.

irregularly corrugated with grooves corresponding to the blood-vessels issuing from the aorta. A similar structure can be seen on the left side of the vertebral bodies D11-D12.

The anterior intervertebral ligament is clearly visible and slightly drawn to the left by the outgrowth. It covers the anterior irregular edge of the protuberance on the right as well as the smaller outgrowth on the left, but does not seem particularly adherent to them.

The sacro-iliac joints are mobile. The facet-joints L2-L3 on the left have swollen and indistinct processes. There is slight mobility at the level of these joints, as shown by the folding of the articular capsules during the movements.

In cutting the sagittal and radial sections of the specimen we found a greater resistance at the level of the hyperostosis; the disks are normal and flexible, and the bony outgrowths show some elasticity, which is entirely lacking in the case of thicker outgrowths.

$X$-Ray Examination.- In the lateral view the bony outgrowths at the front of the vertebral bodies do not seem to merge with them. The disks are normal. At the level of D9-D10 are little osteophytes fused with the bony outgrowth.

The antero-posterior film shows "structural changes" at the level of the vertebrae 
covered by the bony outgrowths. The intervertebral disks are normal; at their outer edges are bony bridgings which might lead to confusion with ankylosing spondylitis. The sacro-iliac joints are not clearly visible here.*

From the point of view of morbid anatomy, this disease is chiefly characterized by the existence of bony outgrowths arising from the whole side of the vertebral bodies and extending upwards over the disk spaces, at which level they are often thickened. These hyperostoses have a bony structure with a dense cortex similar to that of the head of the femur, the cancellous bone being in continuity with that of the vertebral bodies. These outgrowths are usually present in the dorsal spine, but may in some cases extend from the axis to the upper part of the sacrum. They generally cover the right antero-lateral aspect of the dorsal spine; but, opposite the dorso-lumbar joint and in the lumbar region, they may also cover the left antero-lateral aspect and even the medial and anterior surfaces of the vertebral bodies. They seem to be independent of the anterior vertebral common ligament; in fact, in contrast to the ligament, they are more obvious laterally than medially. In the two cases studied at necropsy, the ligament was normal and readily separated from the bony outgrowths. In one of them, where the hyperostosis was situated not only on the right side of the spine, but also anteriorly, the anterior common ligament was displaced towards the left.

The considerable thickening or " budding" of the hyperostoses which often appear at the level of the disks have no connexion with the latter. When large osteophytes are also present, the bony outgrowths cover the osteophytes and thus cause additional bulging in places, but the largest bulges are often found with normal disks at the level of the dorsal spine.

The co-existence of osteophytes with these hyperostotic formations has often caused this disease to be regarded as an advanced form of vertebral osteophytosis (osteo-arthritis of the spine). The results of examining specimens of very advanced osteophytosis and of studying numerous $X$-ray films of cases of severe osteo-arthritis of the spine are, however, entirely opposed to this interpretation. The anatomical features of hyperostosis differ obviously from those of osteophytosis where the bony outgrowths are related to disk changes.

\section{Aetiology}

We have no definite aetiological data. The one constant is old age (average 65).

Severe trauma at onset has been reported in three cases and we consider that trauma may be a precipitating cause of the clinical signs.

Other conditions present in these cases were merely those of old people showing visceral changes due to chronic disease (cardiac deficiency, bronchitis, jaundice).

\section{Pathogenesis}

Our knowledge of the pathogenesis of this disease is small. It is clear that these spinal ossifications do not come from the anterior vertebral common ligament,

* Owing to the war, the preparation of these specimens in dried bones was not possible. 
and it is probable that they arise in the continuous perivertebral fibrous sheath. The latter is composed of short fibres inserted into two adjacent vertebrae and extending in front of the disk space (Rainer's perirachis). But we still have to explain why this fibrous vertebral sheath suddenly produces bone and why this phenomenon occurs in the spine. We have already mentioned that all our patients were men. We know that a vertebral venous and lymphatic system, with extensive anastomoses, exists, connecting the prostate with the entire vertebral region (Meyer and Forster, 1938). Since this gland is frequently pathological in old men, it might be interesting to study the condition of the prostate, its internal secretions and their paths of diffusion, in these patients.

We have lately observed two cases of cancer of the prostate, with metastasis of the osteoplastic type extending to the whole lumbar and dorsal region, together with considerable ossification of the perispinal fibrous sheath with typical features of ankylosing hyperostosis.

\section{Definition of the Condition}

We consider that we have laid down clinical, radiological, and pathological criteria which differentiate a new ankylosing condition of the spine from ankylosing spondylitis. We propose to call this condition "senile ankylosing hyperostosis of the spine". This name emphasizes: $(a)$ the hyperostosis, a most striking pathological element, and $(b)$ two constant clinical features: spinal rigidity and advanced age. It is certainly not a rare disease, but most often either goes unnoticed or is mistaken for some other form of vertebral ossification.

\section{Prognosis and Treatment}

This ankylosing hyperostosis gives little trouble to the patient apart from the spinal stiffness which is well tolerated.

As these patients are elderly and suffer little pain or discomfort, treatment of the spinal disease is seldom indicated. Attention is usually only drawn to the condition by the other organic illnesses of old age, or by additional arthritic symptoms.

\section{Summary}

(1) An ankylosing disease of the spine in old people is described, which may be distinguished from ankylosing spondylitis.

(2) The pathological and radiological features have been studied in nine patients and two necropsy specimens.

(3) $X$-ray films reveal the presence of bony outgrowths or hyperostoses, mainly in the dorsal region, but sometimes extending from the upper part of the sacrum to the axis. They arise from the antero-lateral aspect of the vertebral bodies and grow upwards in a "candle-flame" formation over the lumbar disk spaces; at the level of the dorsal disks they are often thickened. They have a bony structure with a dense cortex similar to that of the head of the femur, the cancellous bone being in continuity with that of the vertebral bodies. They may co-exist with osteophytes, but have entirely different anatomical features. 
(4) Points of difference between this disease, ankylosing spondylitis, and spinal osteo-arthritis are tabulated.

(5) The aetiology and pathogenesis of the condition are discussed.

(6) The condition is defined as " senile ankylosing hyperostosis of the spine".

(7) The mild nature of the symptoms gives little indication for active treatment.

\section{REFERENCES}

Buckley, C. W. (1945). Annals of the Rheumatic Diseases, 5, 49.

Comroe, B. I. (1949). "Arthritis and Allied Conditions", p. 542, fig. 184 . Kimpton, London.

Fagge, C. Hilton (1877). Trans. path. Soc., 28, 201.

Forestier, J., Jacqueline, F., and Rotes-Querol, J. “ La Spondyl-arthrite Ankylosante.” Masson, Paris. (In the press.)

Lacapère, A. (1949). Acta physiothér. rheum. belg., 4, 145.

Léri, A. (1904). Bull. Soc. méd. Hôp. Paris, 21, 875.

(1926). "Etude sur les Affections de la Colonne Vertebrale." Masson, Paris.

Marie, P., and Astié, C. (1897). Pr. méd., 5, 205.

Meyer, M., and Forster, E. (1938). Rev. Rhum., 5, 286.

Oppenheimer, A. (1942). Radiology, 38, 160.

Rainer, F. J. (1945). " "Structure fonctionelle " in " Oeuvre Scientifique ", vol. 2. Academia Română, Bucuresti.

Hyperostose Ankylosante Vertébrale Sénile

\section{RÉSUMÉ}

L'étude clinique et radiologique de neuf malades et l'étude anatomo-pathologique de deux sujets à l'autopsie a permis aux auteurs d'isoler une affection ankylosante du rachis qui se distingue nettement de la spondylarthrite.

L'hyperostose ankylosante vertébrale sénile ne fut constatée que chez les hommes âgés. Cliniquement elle se caractérise par la raideur vertébrale toujours dorsale, souvent lombaire, indolore et peu gênante. Radiologiquement le cliché de profil est le plus caractéristique; il montre au segment dorsal une coulée continue qui borde la face antérieure des corps vertébraux et qui au niveau des disques s'épaissit en grosses boursoufflures. Aux segments cervical et lombaire la coulée, toujours antérieure, est discontinue, coupée au niveau des disques. Les formations osseuses lombaires donnent de curieuses images très exubérantes "en flamme de bougie" se dirigeant vers le haut. L'examen anatomo-pathologique révèle des productions osseuses, avec une corticale dense comparable à celle de la tête du fémur, prenant naissance sur tout le flanc des corps vertébraux et passant en pont sur les espaces discaux. L'hyperostose prédomine au niveau dorsal mais elle s'étend parfois depuis l'axis à la partie supérieure du sacrum.

La position radiographique antérieure de la coulée et l'absence virtuelle de signes subjectifs et sérologiques facilitent le diagnostic différentiel.

\section{Hiperostosis Anquilosante Vertebral Senil}

\section{RESUMEN}

El estudio clínico y radiológico de neuve enfermos y el estudio anatomo-patológico de dos sujetos fallecidos permitió a los autores de aislar una afección anquilosante de la columna vertebral que difiere netamente de la espondilitis.

La hiperostosis anquilosante vertebral senil fué encontrada sólo en hombres viejos. Esta enfermedad se caracteriza clínicamente por una rigidez vertebral siempre dorsal, a menudo lumbar, indolora y poco molesta. Radiológicamente, el perfil es muy característico, mostrando una formación óstea continua a lo largo de la cara anterior de la columna dorsal, más espesa al nivel de los discos. En los segmentos cervical y lumbar esta continuidad está interrumpida al nivel de los discos. Las formaciones ósteas lumbares producen el aspecto muy curioso de "llama de bugía "que se dirige hacia arriba. El examen anatomo-patológico revela formaciones ósteas con la cortical densa semejante a la de la cabeza del fémur. Estas formaciones nacen en el flanco de los cuerpos vertebrales y hacen puente entre los discos. La hiperostosis predomina al nivel dorsal pero a menudo se extiende desde el axis hasta la parte superior del sacro.

La posición radiográfica anterior de las formaciones ósteas y la ausencia virtual de síntomas subjetivos y serológicos facilitan el diagnóstico diferencial. 